\title{
Development and evolutionary constraints in animals
}

Frietson Galis

Naturalis Biodiversity Center

frietson.galis@naturalis.nl

Johan A. J. Metz

University of Leiden

j.a.j.metz@biology.leidenuniv.nl

Jacques J. M. van Alphen

University of Amsterdam

jacques.vanalphen@gmail.com

Running title: Development and evolutionary constraints

Corresponding author:

Frietson Galis

Naturalis Biodiversity Center

Darwinweg 2, 2333CR Leiden,

The Netherlands

$+31648814360$

frietson.galis@naturalis.nl

\begin{abstract}
We review the evolutionary importance of developmental mechanisms in constraining evolutionary changes in animals, i.e. developmental constraints. We focus on hard constraints that can act on macro-evolutionary time-scales.

We in particular discuss the causes and evolutionary consequences of the ancient metazoan constraint that differentiated cells cannot divide, and constraints against changes of phylotypic stages in vertebrates and other higher taxa.

We conclude that in all cases these constraints are caused by complex and highly controlled global interactivity of development, that when disturbed has grave consequences. Mutations that affect such global interactivity almost unavoidably have many deleterious pleiotropic effects, which will be strongly selected against, and lead to long-term evolutionary stasis.

The discussed developmental constraints have pervasive consequences for evolution and critically restrict regeneration capacity and body plan evolution.
\end{abstract}

\section{Keywords:}

Evo-Devo, body plan evolution, evolutionary constraint, parthenogenesis, phylotypic stages, regeneration capacity 


\section{Introduction}

Evolution has produced an astonishing array of organisms, yet the branches of the evolutionary tree do not reach all profitable regions of phenotype space (Maynard Smith et al 1985, Vermeij 2015). Evolution, thus, appears to be subject to constraints. We focus on developmental constraints, that is on the role of developmental mechanisms in restricting the range of possibly adaptive phenotypes (Oster \& Alberch 1982, Müller \& Wagner 1991, Amundson 1994, Schoch 2013). Constraints act on different time-scales, on the level of micro-evolution, meso-evolution and macro-evolution (see Box 1). Discussion on the existence of developmental constraints has in the past primarily focused on genetic constraints, in particular on the potential of genetic covariation due to linkage disequilibrium or pleiotropy to constrain evolution (e.g. Barton \& Turelli 1989, Kirkpatrick \& Lofsvold 1992, Futuyma et al. 1995, Connor 2012). Genetic covariation undoubtedly can have major effects on evolution; however, it primarily acts on micro-evolutionary and at most meso-evolutionary scales and is highly unlikely to cause long term conservation, (e.g. Lande 1980, Connor 2012, Hill \& Zhang 2012, box 1), but see below for relational pleiotropy, sensu Hadorn 1961. We focus on constraints on macro-evolutionary scales

Absolute developmental constraints on the evolution of specific adaptive phenotypes are rare. Vermeij (2015) even postulates that there are no such absolute constraints given sufficient time. We shall argue below that there is one category of near absolute developmental constraints: when development is highly interactive (has low effective modularity), the multitude of cascading pleiotropic effects (relational pleiotropy, sensu Hadorn 1961) results in highdimensional covariation. Mutations with an effect during such highly interactive stages will almost unavoidably have a multitude of pleiotropic effects, that will be strongly selected against, and thus will constrain the evolution of traits even on macro-evolutionary scales (Galis \& Metz 2001, Galis et al. 2002a). Hence, such traits will be conserved due to consistently strong stabilizing selection caused by pleiotropic effects (Lande 1978, Hansen \& Houle 2008, Futuyma 2010).

We found very few well-documented examples of developmental constraints that act long term. We shall discuss what we think are the outstanding examples of such near absolute developmental constraints in animals, as well as their causes and evolutionary impacts: the metazoan constraint that differentiated cells cannot divide, and the constraints against changes of phylotypic stages in vertebrates and other higher taxa.

\section{An ancient metazoan constraint: cells cannot divide while differentiated}

In 1898, Henneguy and Lenhossek were the first to hypothesize, independently, that ciliated cells of metazoans are not capable of cell division. They had both noticed that the basal bodies of cilia were transformed centrosomes and both also remarked to have never seen a ciliated cell divide. Based on this they hypothesized that in cells where the centrosome has lost its ability to form a spindle and has become involved in cilium formation, cell division is not anymore possible, at least not by mitosis. Both processes need the centrosome and are, therefore, mutually exclusive. A newly formed cell has one centrosome, composed of two centrioles (an older mother and a younger daughter centriole) surrounded by a protein-rich matrix called pericentriolar material (PCM). The centrosome is duplicated during the $\mathrm{S}$ phase of the cell cycle, so that during mitosis there are two centrosomes to form the two poles of the spindle. In addition one of the centrioles also serves as basal body of a cilium or flagella (Brinkley et al. 1985, Wu \& Akhmanova 2017). Indeed, several studies have found a negative correlation between the presence of cilia and mitotic activity, supporting the hypothesis (Dingemans 1969, Fonte et al. 1971). Buss (1987) 
extended the constraint and proposed that in metazoans there is a universal constraint on the division by mitosis of not only ciliated but all differentiated cells, as he assumed that the cilium is usually involved in the differentiation process of a cell (see also Bell 1989). His reasoning is similar, although he ascribed the idea to Margulis (1981) instead of to Henneguy (1898) and Lenhossek (1898), presuming that there is in metazoan cells only one microtubule organizing center (MTOC), the centrosome, and that any commitment of a single MTOC, whether to a cilium or to another microtubule-based structure, would preclude commitment to the poles of the mitotic spindle, thus preventing mitosis. Thus, stem cells and progenitor cells can divide and ciliated cells cannot, unless they dedifferentiate and resorb the cilium, as happens in regeneration (Tanaka \& Reddien 2011) and cancer (Schwitalla et al 2013). Buss further proposed that the constraint is a phylogenetic one, given that 'evolution can only yield variants of that which it has already produced' (page 34). He argued that metazoans inherited the limitation of having only one microtubule-organizing center and not more from their unicellular protist ancestors and that in contrast, other unicellular groups, such as Euglenophytes, Cryptophytes, and Chlorophytes possess multiple microtubule- organizing centers, and therefore do not have this constraint. These groups are capable of accomplishing simultaneous cell movement and mitotic cell division, by using some centers exclusively as organizers for undulipodia (cilia, flagella), and others for cell division).

\section{Challenges to Buss's hypothesis}

Bell (1989) stressed the importance of the proposals of Buss, but disagreed with the interpretation of a phylogenetic constraint. Bell argued that it is not likely that metazoans are limited by their inability to generate more than one centrosome, given that they are capable of duplicating centrosome in every cell cycle: the two centrioles of the centrosome are each duplicated during $\mathrm{S}$ phase and both form a new centrosome together with the duplicated copy of themselves (a mother and daughter centriole). Thirty years later, the rapidly expanded knowledge of cellular dynamics has revealed several further challenges to Buss's hypothesis. Experimental removal of centrosomes has shown that they are not essential for the formation of radial spindles and mitotic cell division (e.g. Bonaccorsi et al. 2000, Basto et al. 2006). Some cells normally divide without a centrosome in early development (Courtois et al 2012, Zenker et al. 2017). Centrosomes have been evolutionarily lost in planarian flatworms (Azimzadeh et al. 2012) and there are several non-centrosomal microtubule organizing centers (MTOCs) in one cell, in particular when cells are differentiated (Rios 2014, Wu \& Achmatova 2017). Furthermore, as Bell (1989) expected, an extra centrosome is exceptionally formed in cells (Tsou \& Stearns 2006, Gönczy 2015) and some cells have many centrioles and cilia.

As we will describe, novel information on the key roles of the centrosome and cilium in cell division/proliferation and differentiation explains why there can normally be only one centrosome in a cell and not more, why the multiple non-centrosomal MTOCs cannot organize radial mitotic spindle poles in differentiated cells, and why the functions of the centrosome in mitotic spindle formation and ciliogenesis are mutually exclusive.

\section{Centrosomes and mitotic fidelity}

Centrosomes are duplicated precisely once per cell cycle. During mitosis, the duplicated centrosomes form bipolar spindles that accurately segregate the duplicated chromosomes, 
producing an equal distribution of chromosomes between daughter cells (e.g. Sir 2013, Meraldi 2016). Centrosomes are not absolutely required for mitotic spindle formation and division in many cells (e.g. Bonaccorsi et al. 2000, Basto et al. 2006Meraldi 2016). but mitosis in the absence of centrosomes is an error-prone process and centrosomes appear to be necessary for rapid, robust and error-free separation of the chromosomes during mitosis (Basto et al. 2006, Sir et al 2013, Meraldi 2016, Lattao et al. 2017).

\section{Additional functions of the centrosome.}

Centrosomes have been found to have many different roles during cell proliferation and differentiation. For instance, they play a major role in cell cycle control, establishing cell polarity and the positioning of cell organelles, transmission of polarity to daughter cells, and adhesion, de-epithelialization and migration of cells (e.g. Bornens 2012, Wu and Akhmanova 2017, Burute et al. 2017). They also function as signaling hubs, involved in DNA damage repair (Conduit et al 2015, Farina et al 2016). Furthermore, centrosomes play a major role in the specification of cell fate during asymmetric divisions (e.g. Haubensack et al. 2004, Yamashita et al. 2007, Dudka \& Meraldi 2017). This hinges on a presumably causal role of the asymmetry of the centrioles in the centrosome. The two centrioles of a centrosome are of different age (mother and daughter), with the older centriole having accumulated more pericentriolar proteins. After duplication, one centrosome has the duplicated mother centriole and the other has the duplicated daughter centriole.). Asymmetric cell divisions involve the differential partitioning of the two unequal centrosomes over the daughter cells, with one daughter cell renewing the stem cell (usually the one with the mother centriole) and the other initiating a differentiation path (Rebollo et al 2007, Roubinet \& Cabernard 2014). Thus, in addition to the central role in separation of the chromosomes, the centrosome plays a crucial role in cell cycle control and cell fate decisions.

\section{Loss of centrosomes in planarians.}

The freshwater planarian Schmidtea mediterranea does assemble centrioles that function as basal bodies of cilia in multiciliated cells, but centrioles are not involved in cell division (Azimzadeh et al. 2012). No centrosomes are formed and centrosomal proteins are absent, challenging the importance of the centrosome for mitosis in these metazoans. The loss of centrosomes in this species is thought to be related to the loss of spiral cleavage and oriented cell divisions. This hypothesis is supported by the presence of centrosomes in the basal, roundshaped, non-planarian, flatworm Macrostomum lignano, which has retained the ancient spiral cleavage and the associated oriented cell divisions (Azimzadeh et al. 2012, Bornens 2012, Wu \& Akhmanova 2017, but see Martin Duran \& Egger 2012). A factor that may have played a role in the loss of centrosomes in planarians is that the reliable separation of a few chromosomes $(2 n=8)$ is technically less difficult than in organisms with a large number.

\section{Other centrosomes.}

Exceptionally, de novo generation of extra centrosomes occurs. Not surprisingly, given the above-mentioned functions of the centrosome, extra centrosomes pose a grave risk and may lead to the formation of multiple spindle poles, aneuploidy, cell cycle arrest, apoptosis, genomic instability, cell migratio, (e.g. in metastasis of cancer cells; Tsou \& Stearns 2006, Basto et al 
2008, Godinho \& Pelman 2014, Gönczy 2015), and perhaps cancer, as first proposed by Theodor Boveri (1902) and experimentally shown in Drosophila and mice (Basto et al. 2008, Levine et al. 2017; but see Gönczy 2015, Godinho \& Pelman 2017, Raff \& Basto 2017). . The importance of having only one centrosome per cell is also supported by the elimination of the centrioles from animal egg cells before fertilization, such that the zygote only receives centrioles from the sperm cell and does not end up with two centrosomes (Boveri 1901, Bell 1979, Manandhar et al. 2005). We conclude that supernumerary centrosomes are usually seriously disadvantageous for the individual and will be strongly selected against. It is therefore unlikely that the inability of ciliated cells to form proper mitotic spindles could be compensated by extra centrosomes

\section{Non-centrosomal MTOCs}

During differentiation, the microtubule-organizing capacity is partially or fully transferred from the centrosome to other cellular structures that organize the microtubules in cell type-specific arrays, suitable for specialized cell functions, other than mitosis (e.g. Sanchez et al. 2016,Wu \& Akhmanova 2017), so-called non-centrosomal MTOCs. Examples of non-centrosomal MTOCs are the Golgi apparatus, the nuclear envelope, chromatin and kinetochores, the cell cortex and pre-existing microtubules (Chabin-Brion et al. 2001, Stiess et al. 2010, Maia et al. 2013, Rios 2014, Sanchez et al. 2016, Wu \& Akhmanova 2017). These structures organize microtubuli in non-radial geometric patterns, associated with their different functions, e.g. the Golgi apparatus is involved in the reorganization of the cellular architecture during the differentiation of muscle and nerve cells (Rios 2014). The division of tasks between the centrosomal and non-centrosomal MTOCs appears to be tightly regulated during cell cycle progression and differentiation, possibly in a competitive way (Wu \& Achmanova 2017). Cells with non centrosomal MTOCs capable of both microtubule nucleation and anchoring appear to inactivate these functions at the centrosome and to transfer them to the non-centrosomal site (Wu \& Achmanova 2017), possibly, because similar multiprotein complexes are involved in both processes.

\section{Centrosome and formation of primary cilium}

Centrosomes change dynamically during the cell cycle. They are duplicated once per cell cycle with, as mentioned above, precisely one new centriole assembled adjacent to the mother centriole and one adjacent to the daughter centriole. The two centrosomes then form bipolar spindles that distribute chromosomes equally between two dividing cels (e.g. Sir 2013, Meraldi 2016). At the exit of mitosis cells typically form a primary cilium, unless they continue proliferating, when ciliogenesis appears to be actively suppressed (Goto et al. 2017). In all other cases, also in quiescent stem cells, the mother centriole converts to a basal body and migrates to the cell surface where it docks to the cell membrane and assembles the primary cilium that protrudes from the cell membrane. The centrosome remains intact, as the mother and daughter centrioles migrate together and remain associated throughout ciliogenesis (Sorokin 1968, Alieva $\&$ Vorobjev 2004). Upon cell-cycle re-entry, ciliary resorption begins, the basal body is detached from the cell surface and the centrosome migrates to near the nucleus. 


\section{Importance of primary cilia}

Primary cilia were long thought to be vestigial organelles, which would complicate the reasoning of Buss that the presence of cilia forms a hard constraint for the use of centrioles for mitotic spindles. Furthermore, only in the nineteen-nineties, due to technical improvements of visualization techniques, it became known that primary cilia are present as antennae on almost all metazoan cells (Wheatley 1995). Since then, it has become apparent that they do not only function as sensory organelles, but also have a key function in intercellular signaling (e.g. Dawe et al. 2007, Ludeman et al. 2014, Walz 2017). Signaling in the cilium is involved in the organization of most, if not all developmental processes, including left-right patterning, cell migration, re-entry of cells into the cell cycle (proliferation), cell size, cell shape, specification of the plane of cell division, apoptosis and cell fate decisions. For example, in vertebrates an important role of cilia is the coordination of a many pathways, including the Sonic hedgehog (Shh),Wnt, TGFB, LKBI and Hippo pathways (Breunig et al. 2008, Ohazama et al. 2009, Lancaster et al. 2011, Basten \& Giles 2013, Ke \& Yang 2014, Walz 2017). Underlining the crucial importance of cilia in development and tissue homeostasis is the wide range and common occurrence of diseases that are caused by dysfunctional cilia, so-called ciliopathies, which include left-right patterning defects, polycystic kidney disease, retinal degeneration, diabetes, Meckel Gruber syndrome, microcephaly and cancer (e.g. Wheatley 1995, Basten \& Giles 2013). Furthermore, in cells with supernumerary centrosomes, extra cilia are often formed and these compromise the functioning of primary cilium signaling and may lead to cancer and other diseases (Mahjoub \& Stearns 2012). Thus, far from being vestigial organelles, primary cilia are of vital importance and cannot be missed. This is, as we will see below, an important cause of the constraint.

\section{Multiciliated cells}

Some cells in animals can have hundreds of cilia, each requiring its own basal body to be assembled de novo. (Dawe et al. 2007, Basten \& Giles 2013). However, the pathways used to produce these centrioles are different from those used during duplication of the centrioles during the cell division cycle and are linked to differentiation rather than to proliferation. Multiciliated cells are terminally differentiated (Dawe 2007, Basten \& Giles 2013); for cell renewal, unciliated progenitor cells are employed (Evans et al. 1986, Bird et al. 2014). Hence, despite the large number of centrioles, these multicilliated cells do not form an exception to the rule that differentiated cells can not divide.

\section{The centrosome cycle regulates the cell cycle}

Recent research has shown that the cell cycle is not so much regulating centrosome and cilium dynamics, but contrastingly, the dynamics of the centrosome and primary cilium actively regulate cell cycle progression and arrest or exit followed by differentiation (Masuda \& Sato 1984, Basten \& Giles 2013, Goto et al. 2013; 2017, Ke \& Yang 2014, Gabriel et al. 2016, Walz 2017). For instance, the presence of the primary cilium appears to block cell division, while primary ciliary resorption is thought to unblock cell division and the length of the cilium influences cell cycle duration, with cell cycle length influencing cell fate decisions. 


\section{Pleiotropic constraint on changes of centrosome number}

Cellular dynamics in multicellular metazoans is, thus, extremely complex and the centrosome and primary cilium are key players regulating almost all major cellular processes including mitosis and differentiation. A further contribution to the complexity and tight interactive control comes from the competitive interactions between the centrosome and non-centrosomal sites that organize microtubuli. As a result, mutations affecting centrosomal and ciliary functions have many deleterious pleiotropic effects, that can have an impact on cell cycle progression and may cause apoptosis, genomic instability, aneuploidy and cancer (e.g. Boveri 1902, Göncy 2015, Godinho \& Pelman 2014, Dudka \& Meraldi 2017). As a consequence of the pleiotropic constraint there is only one centrosome in a cell and this can function either in cell division or in ciliation and differentiation. The pleiotropic constraint causes a developmental constraint, ciliated and differentiated cells cannot divide by mitosis. In metazoans a pleiotropic constraint is, thus, most likely the cause of the strong conservation of the dynamics of the centrosome and primary cilium that regulate the cell cycle, including the number of centrosomes, with as sole exception thusfar, planarians that have lost centrosomes (Azimzadeh et al. 2012). As Buss (1987) has lucidly pointed out, the uncontrolled proliferation of individual cell lineages is the major challenge to be overcome by multicellular individuals in the early evolution of multicellularity. Once the control is at the level of the individual, there will continue to be strong anti-cancer selection against mutations that lead to unchecked proliferation of cell lineages (Galis \& Metz 2003).

The pleiotropic constraint is associated with a cost of lower fidelity of meiotic divisions in the ovum, as the centrosome in all animal ova is degenerated, presumably to avoid the problematic presence of a second centrosome in the zygote. It is thought that the centrioles of the oocyte rather than of the spermatocyte are degenerated because of the necessity for the motile sperm cell to have a centriole organizing its tail (Manandhar et al. 2005). Thus, the acentriolar spindle formation during oogenesis can be expected to lead to increased rates of aneuploidy.

\section{Developmental constraint}

A direct consequence of the strong pleiotropic constraint in metazoans is a developmental constraint: ciliated and differentiated cells cannot divide by mitosis, unless they first dedifferentiate, as occurs for instance in regeneration and in cancer.

The hypothesis of Henneguy (1898) and Lenhossek (1898) that ciliated cells cannot divide by mitosis remains thusfar uncontested for metazoans. As virtually all differentiated cells appear to have a primary cilium, this essentially equates the hypothesis to the one of Buss, that there is a constraint on mitotic divisions of differentiated cells. Even lymphocytes that were long thought to be exceptional as not having primary cilia, are now thought to have a modified primary cilium (Finetti et al. 2009, Dustin et al. 2014). Furthermore, in the differentiation of some cells the cilium or centrosome is discarded, which also prevents further cell division (Bornens 2012, Srsen et al. 2009, Storey 2014). The few claims that differentiated cells can divide during cell renewal and regeneration, are controversial(Dor 2004, Teta et al. 2007, Brennand et al 2007 Afelik \& Rovira 2017,Smukler et al. 2011, Razavi et al 2015, Beamish et al. 2016, West Phalen et al. 2016). 


\section{Evolutionary consequences of the developmental constraint}

The constraint that cells can either divide or differentiate has a pervasive influence on the evolution of metazoans. It is a major force in shaping development, regeneration and the evolution of body plans.

Buss postulated that metazoans inherited the constraint from their unicellular protist ancestors, and that their inability to both divide and to move with a cilium provided a selective advantage for multicellularity (see also Trestman 2013). Multicellularity allows a division of labor with some cells taking care of mobility and feeding and some undergoing mitosis. Buss further proposed that the evolution of gastrulation in early free-living metazoans is a consequence of the constraint, because ciliated dispersing blastulas can only continue to develop when ciliated cells from the outside migrate inward and prepare for mitosis by retracting their cilia, leaving as many ciliated cells as possible on the surface. Bell (1989) argued instead that gastrula formation with flagellated cells on the outside and unflagellated cells on the inside may be a selectively advantageous hydrodynamic configuration. Be this as it may, there is no doubt that the incompatibility of simultaneous cell division and ciliation has crucially shaped developmental processes, with zones that produce pluripotent stem cell colonies that subsequently migrate to other places in the embryo, to initiate their paths of differentiation. Additionally, signaling pathways are of major importance for all aspects of development and, as we now know, cilia are required for the coordination of many signaling pathways; hence, this coordination cannot happen when cells are dividing. Furthermore, niches of tissue-specific progenitor cells must be developed and maintained in adult tissues and organs to function in cell renewal, wound-healing, and regeneration (Tanaka \& Reddien 2011).

Wound healing and regeneration would presumably be much more effective if all differentiated cells could divide to replace damaged cells of the same type. Regeneration now typically proceeds from a blastema of undifferentiated cells that are either dedifferentiated or already locally present progenitor cells (Brockes 1997, Tanaka \& Reddien 2011). Complex interactions then are required, often similar to those that occurred during development of the to be regenerated part (Galis et al. 2003). This requirement of developmental interactions after dedifferentiation seriously limits the possibility of regeneration in many metazoans, at least in more complex ones (see phylotypic stages, below). It is perhaps not accidental that Schmidtea mediterranea, which has lost centrosomes and does not employ them for spindle formation in mitosis has virtually unrivalled powers of regeneration, whereas the platyhelminth Macrostomum lignano, which has not lost centrosomes has a more limited capacity for regeneration (Azimzadeh et al. 2012, Bornens 2012). S. mediterranea and other planarians have broadly distributed adult stem cells, (neoblasts), some of which are totipotent and as a result small pieces of tissue can reconstitute the entire organism (Baguñà \& Auladell 1989, Gentile et al 2011, van Wolfswinkel et al. 2014). Adult stem cells in most other metazoans have lost pluripotency and are fate-restricted progenitor cells, which limits the regenerative capacity.

In addition, the conflict between ciliation and mitosis powerfully constrains the evolution of body plans. Unlike in plants, in which new organs like branches and leaves can develop during adult life, we cannot grow an extra arm or eye. In almost all metazoans the evolution of the number of organs is constrained. The specification of complex body parts must happen early on in the embryo, usually during early organogenesis. The most flexibility is provided by changes in the number of segments, which allow the multiplication of legs and other organs of the segment (see paragraph on centipedes below). Another solution to this problem is 
the vegetative production of modules that are morphological repeats of the body plan, as for instance found in cnidarians, bryozoans and colonial ascidians (Bell 1982). With increasing complexity, the constraint against simultaneous differentiation and division, thus, will have a stronger influence on the conservation of development (cf. section on phylotypic stages).

Finally, the constraint against having more than one centrosome in a cell leads not only to a low fidelity of meiotic divisions as discussed above, but also provides a powerful developmental constraint against parthenogenesis, A centrosome is generally necessary to initiate mitotic divisions (e.g. Riparbelli et al. 1998, Eisman and Kaufman 2007, Bornens 2012), hence the absent paternal contribution of centrioles to the oocyte lowers the chance for successful mitoses of the unfertilized zygote. The problem of the missing centrosome in unfertilized ova in obligatory or regularly parthenogenetic animals is usually solved by the de novo assembly of a centrosome (e.g. Riparbelli et al. 1998, Tram and Sullivan 2000, Riparbelli \& Callaini 2003, Ferree et al. 2006, Hiruta and Tochunai 2012). Special adaptations have evolved for this, e.g. special cytoplasmic organelles (accessory nuclei) in haplodiploid insects (Tram \& Sullivan 2000, Ferree et al. 2006). In contrast, in sporadic parthenogenesis, it leads to malfunctioning centrosomes that interfere with proper mitosis and ploidy restoration (Eisman \& Kaufman 2007). In Drosophila mercatorum, problems with the de novo assembly and maturation of centrosomes are an important contributor to the high rates of early embryonic death, contrasting with the high hatchability and viability of the obligately parthenogenetic $D$. mangabeirai (Riparbelli \& Callaini 2003, Eisman \& Kaufman 2007). Another solution for the absent centrosome is found in species that utilize sperm dependent parthenogenesis, gynogenesis (pseudogamy) or hybridogenesis. In gynogenesis, a sperm cell of a related sexual species or conspecific is necessary to initiate mitosis of the ovum, but the sperm does not contribute genes (Beukeboom \& Vrijenhoek 1998, Lamatsch \& Scharl 2010). It is generally assumed that the centriole is the paternal contribution that is necessary to initiate mitosis after centrosome formation (Tournier \& Bornens 1987, Riparbelli et al 1989).

\section{Phylotypic stages}

Embryologists have long noticed that within many higher order taxa, e.g. phyla or classes, early organogenesis is less variable morphologically than both the earlier stages of cleavage and gastrulation and the later stages (e.g. Seidel 1960, Sander 1983 , Hall 1997). Recently, many studies have shown that during early organogenesis there is also strong conservation of the expression of genes. This was first observed for Hox genes (Slack et al. 1993, Duboule 1994) and subsequently for many other genes, in particular regulatory ones (e.g. Davis et al. 2005, Domazet-Lošo \& Tautz 2010. Kalinka et al. 2010 ; Irie \&Kuratani 2011, Levin et al 2012, Ninova et al. 2014, Drost et al. 2015, Hu et al 2017, see also Cheng et al. 2015). The conservation includes not only expression of genes, but also DNA sequences, and was found to correspond with high evolutionary gene ages (Domazet-Lošo \& Tautz 2010, Hu et al 2017). Furthermore, epigenetic mechanisms, such as demethylation of specific embryonic enhancers, were found to be conserved in vertebrates at this stage (Bogdanović et al 2016)., Some support has also been found for conservation of earlier stages (e.g. Piasecka et al. 2013). Sander (1983) came up with the term phylotypic stage and the attendant concept, although nowadays the concept is extended to other higher taxa than phyla, e.g. classes in insects. an extension, which in the past has generated some controversy (Scholtz 2000). Note that the conservation is not be taken overly strictly, what matters is that in many higher taxa development is remarkably 
conserved during phylotypic stages, stronger than during earlier or later embryogenesis (Galis et al. 2001, Sander \& Schmidt-Ott 2004)..

\section{Global interactivity, pleiotropy and stabilizing selection}

As in mitosis, it has been hypothesized that the complex and highly controlled global interactivity of early organogenesis in the embryo causes strong pleiotropic constraints against evolutionary change (Sander 1983, Raff 1996). Strong global interactivity contrasts with effective modularity of development. It causes even slight disturbances to cascade into deleterious pleiotropic effects in other parts of the embryo, and these become amplified as development proceeds. The result isstrong stabilizing selection against changes (Galis et al. 2001, 2002a, Kalinka et al. 2010). Thus, in this scenario, deleterious pleiotropic effects and stabilizing selection against these effects are key to the conservation. We have called this the pleiotropy hypothesis (Galis et al 2002a). We will discuss the rapidly growing body of empirical support for the pleiotropy hypothesis and will also discuss why evolutionary constraints for change of earlier and later stages are weaker.

\section{Vulnerability and interactivity of mammalian phylotypic stages}

Teratological data on rodents strongly support the pleiotropy hypothesis: early organogenesis was found to be more vulnerable to disturbances than earlier or later stages, because disturbances led to more lethality and abnormalities (Galis and Metz 2001). The pattern of multiple induced abnormalities (pleiotropic effects) indicates that high interactivity and effective modularity is the root cause of the vulnerability of the stage. Hence, the vulnerability is not due to one vulnerable process (e.g. neural tube closure), as is the case with cell division in cleavage (see below), but due to the global interactivity. This implies that a particular, potentially useful, change of this stage, e.g. the induction of an extra digit, almost always will induce other abnormalities and lethality even before the organism is exposed to ecological selection. For example, in humans $\sim 90 \%$ of individuals with a supernumerary digit are dead at birth (Opitz 1987, Galis et al. 2010) and a multitude of deleterious pleiotropic effects is associated with this abnormality (Galis et al. 2001, Biesecker 2011). Similarly, induction of a change of the highly conserved number of seven cervical vertebrae (usually manifested as a cervical rib, i.e. a partial rib on the seventh vertebra) virtually always leads to early lethality: $\sim 90 \%$ of the individuals with a cervical rib are dead at birth and there is a strong association with cardiovascular, nervous, urogenital, and other abnormalities (Galis et al 2006, ten Broek et al. 2012). Additional selection against cervical ribs, after birth, comes from a significant association with childhood tumors (Galis 1999, Galis \& Metz 2003). Cervical ribs are extremely common, found in $\sim 50 \%$ of deceased fetuses and infants (vs. $\sim 1 \%$ in the general population). This implies that an astonishing $\sim 8 \%$ of human conceptions appears to die after disturbances of early organogenesis, which emphasizes the vulnerability of the stage (Galis et al 2006, see also Reumer et al. 2014, van der Geer \& Galis 2017). As organ primordia typically originate during the phylotypic stage, this implies that the conservation of the stage leads to conservation of the number and earliest development of most organs (e.g. lungs, kidneys, limbs, eyes, ears; see paragraph on body plans). 


\section{Vulnerability and conservation}

Early embryonic cleavage is vulnerable to toxicants and radiation, albeit at relatively high doses (e.g. Russell 1950, Shenefelt 1972, Galis \& Metz 2001, Jacquet 2004). However, in contrast to early organogenesis, the vulnerability of cleavage has not led to strong conservation, at least not within insects or vertebrates. This is probably because the dividing cleavage cells are all highly similar and capable of self-renewal: either too many cells are killed and the embryo dies, or the damage is reversible and development proceeds largely normally (Russell 1950, Shenefelt 1972). This is called the "all or none" phenomenon in medicine (Jacquet 2004, Adam 2012). The crucial difference from phylotypic stages is that the vulnerability is caused by disturbances that mainly affect one sensitive process, cell division. In the phylotypic stage, the strong global interactivity restricts the potential for reversal of damage. Mutations that affect earliest development presumably have more of a chance to be successful, as it is more difficult to destabilize a simple pattern than a more complicated pattern. In this spirit, Galis \& Sinervo (2002) hypothesized that the weaker conservation of type of cleavage and gastrulation is probably due to the greater simplicity of the early forms.

\section{Developmental fields, modularity and pleiotropy}

The global interactivity and low effective modularity of phylotypic stages is probably largely because this early in development there are only a few developmental fields and few signaling centers (Opitz et al 2002). Galis et al (2006) proposed that the low developmental robustness of early organogenesis in vertebrates results from the well-documented interactions between the patterning of the three body axes and the coupling of axial patterning with simultaneously occurring morphogenetic processes, such as the division and migration of cells, cell shape changes, segmentation (somitogenesis) and the active maintenance of the bilateral symmetry of somites (e.g. Diez del Corral et al. 2003; Cordes et al. 2004; Ninomiya et al. 2004; Vermot \& Pourquie 2005; Durston et al. 2011). The opposing and antagonistic gradients of Fgf/Wnt and retinoic acid (RA) in interaction with the segmentation clock play a major role in the coordinated organization of these processes. In addition, many auto-regulatory and crossregulatory interactions, including physical interactions, provide feedback to these organizers, which adds to the interactivity in this developmental field that occupies a large part of the embryo, in particular the trunk (loc.cit.). Another large developmental field during this stage is the neural crest-related cardiocraniofacial developmental field (Grifone \& Kelly 2007, Keyte \& Hudson 2012). Hence, the large size of the developmental fields and the intense signaling both within and between them probably cause a major part of the pleiotropy in space associated with the phylotypic stage. Additionally there is pleiotropy in time due to cascading downstream effects in later stages. Furthermore, many of the conserved transcription factors active at this stage, including HOX, as well as common signaling pathways such as TGF-beta, Hedgehog, Fgf, and Wnt, are known to be also active at later stages (although for more restricted functions) which could cause additional pleiotropy (e.g. Sakata \& Chen 2011, Akhshabi et al. 2015). Data on deceased human fetuses and infants provide strong support for the coupling of axial patterning and morphogenetic processes as a cause of the vulnerability (ten Broek et al. 2012). The pattern of abnormalities in $\sim 1300$ cases shows a significant association between defects of A-P patterning of the paraxial mesoderm (in particular cervical ribs) with defects of left-right patterning, midline formation, segmentation (somitogenesis) and neural crest 
development (Ten Broek et al. 2012). The authors found that segmentation defects were nearly always associated with cervical ribs and other vertebral patterning changes ( $98 \%)$, supporting the debated hypothesis that the segmentation clock influences Hox patterning (Zakany et al. 2001, Dubrulle et al. 2001; Cordes et al. 2004; Deschamps \& Duboule 2017). In contrast, there was no significant relationship with the germlayer of origin of the associated abnormalities, supporting the primary importance of global signaling interactions during this stage.

\section{Modularity of later stages}

As development proceeds,progressively more and more signaling centers appear, organizing more and more localized developmental fields: development becomes more compartmentalized. Concomitantly, the expression patterns of key signaling molecules become more restricted.

For instance, the large neural crest-related cardiocraniofacial field becomes over time subdivided into more developmental fields, including the secondary heart field, which in turn gives rise to further subdomains that each act as a developmental field (Grifone \& Kelly 2007, Vincent \& Buckingham 2010, Kelly 2012). Another example is the increased compartmentalization of somites (e.g. Chen et al. 2013). Within these more restricted developmental fields intense signalling between tissues continues to occur, but the interactivity between modules becomes increasingly less important than within modules, presumably resulting in a larger developmental robustness and higher effective modularity (Opitz et al. 2002, Galis et al. 2002a). As a result, pleiotropic constraints and stabilizing selection become gradually less important, allowing more evolutionary divergence of later stages.

\section{Transcriptomic support for pleiotropy}

Recently, transcriptomic studies in many different organisms, even in plants and fungi, have supported that conservation of expression of genes tends to follow an hourglass pattern, with conservation most often strongest during mid-embryogenesis in a wide number of organisms. In particular, support for the conserved expression during mid-embryogenesis was found for regulatory genes, including expression of microRNA genes (Kalinka et al. 2010, De Mendoza et al. 2013, Stergachis et al. 2013, Ninova et al. 2014, Yanai et al. 2016), genes with pleiotropic activity in other parts of the embryo (Cheng et al 2014, Cridge et al 2016, Hu et al. 2017), and those with pleiotropic activity at other stages during development (Levin et al. 2012, Hu et al. 2017, see also Fish et al. 2017). The spatial and temporal pleiotropy can be explained by the above-mentioned global interactivity during the patterning of the three body axes and the associated downstream effects at later developmental stages. The transcriptomics studies are, thus, in good agreement with the morphological studies and support the pleiotropy hypothesis.

\section{Physical processes as important contributors to pleiotropy}

It is regularly suggested in molecular studies that the conservation of gene expression of phylotypic stages is the cause of the morphological conservation. However, this underestimates the crucial importance of (self-organizing) chemical and physical processes, (Karsenti et al 2008). Physical and simple chemical processes play a major role in e.g. chemotaxis, cell division, cell migration, segmentation and convergent extension and as such in all morphogenetic 
processes going on during phylotypic stages (Galis et al. 2006, Salazar-Ciudad \& Jernvall 2010, Stuart Newman 2011, ten Broek et al. 2012, Nelemans et al in press). For these processes, spatial scales are important, as diffusion and viscous coupling work over short distances. Chemical and physical processes are, thus, among the key players in the global interactiveness of the small phylotypic stages, that lead to the widespread pleiotropy, which, together with stabilizing selection appears to be the root cause of the conservation of the phylotypic stage, in at least vertebrates and insects.

\section{Robustness cannot cause long term conservation}

Hu et al (2017) conclude from a study on eight chordates that pleiotropic constraints are involved and that the conservation is stronger for the subphylum of vertebrates than for the chordate phylum as a whole. As an aside, they propose that developmental robustness may be an additional cause for the conservation of the phylotypic stage in vertebrates. This hypothesis, which we have called the robustness hypothesis (Galis et al 2002a), was also proposed by von Dassow and colleagues $(1999,2000)$ for the conservation of the phylotypic stage of insects, the segmented germband stage. They proposed that the robustness of the segment polarity network in each segment should provide a buffer against phenotypic effects of mutational changes of the segmented germband stage. In robust gene networks, by definition, developmental noise and mutations do not lead to clear phenotypic effects because gene interactions neutralize perturbations and in particular make mutations recessive (Wagner 2000, Gibson and Wagner 2000). The robustness and pleiotropy hypotheses are, thus, diametrically opposed: the one proposes that the phylotypic stage is vulnerable to mutational change, but that mutations have large deleterious effects and the other that the effect of mutations will have minimal phenotypic effects and mainly produce cryptic variation. For the phylotypic stage in vertebrates and Drosophila, an abundance of phenotypic variation has been documented, which is for the most part strongly deleterious (Galis et al. 2001, 2002a, 2006, ten Broek et al. 2012). This strongly contradicts the robustness hypothesis (see for a test of the two hypotheses in Drosophila, Galis et al. 2002a). In rodents and humans almost all major congenital abnormalities find their origin in disturbances of the phylotypic stage (Russell 1950, Shenefelt et al 1972, Khera 1984, Sadler 2010). Thus, although there is undoubtedly extremely strong selection for the robustness of early organogenesis, the number of interactions involved in morphogenetic patterning is probably too limited to organize the pattern in an independent, modular way, thwarting the drive for greater robustness (Galis et al. 2002).

Theory also does not support robustness as a cause for long term conservation. Stabilizing selection is expected to lead to robustness to protect optimized traits against developmental noise and mutations (Wagner 2000, Galis et al. 2002, Metz 2011, Papakostas et al. 2014, Austin 2016, Melzer \& Theissen 2016). This robustness can produce short-term conservation. However, in the long term cryptic variation will accumulate, which in high dimensional trait space will lead to diversification of genetic backgrounds and to access to an increased number of new phenotypes (Gibson and Wagner 2000, Galis et al 2002a, Metz 2011, Wagner 2012, Siegal \& Leu 2017). Hence, during periods with drastic environmental changes that lead to strong directional selection, the robustness of development can never be sufficiently high to prevent change, due to the accumulated cryptic variation. In fact, in the long term, cryptic variation is expected to lead to increased evolvability (Wagner 2012, Melzer and Theissen 2016, Siegal and Leu 2017). 


\section{Convergence and divergence of cleavage and gastrulation}

Paradoxically, when we compare between metazoan phyla, gastrulation and cleavage are sometimes remarkably similar morphologically and more so than phylotypic stages (Gilbert \& Raunio 1997, Galis \& Sinervo 2002). Analyses of gene expression patterns confirm this pattern (Levin et al. 2016b). Without doubt similarity is largely unavoidable, given the complete reset that occurs at the initial single-celled stage (Galis \& Sinervo 2002). Only a limited number of permutations are possible in embryos with a few undifferentiated cells. Furthermore, the universal metazoan constraint that cells can only divide while undifferentiated makes an initial cleavage stage with predominantly cell division unavoidable. Further reasons for similarity are caused by convergent locomotory and nutritional adaptations, and maternal attempts at dictating offspring features (Buss 1987). A good example of convergent nutritional adaptations is the development of an embryonal disk on top of yolk in species with yolk-rich embryos, as yolk impedes cleavage (e.g. cephalopods, fishes, reptiles and birds). Gastrulation processeses, on the other hand, are diverse, yet again there is important convergence and this is probably due to both the similarity in the outcome of cleavage processes and the similarity of locomotory and feeding adaptations (reviewed in Buss 1987 and Galis \& Sinervo 2002). Yet, within phyla and classes the process of gastrulation is far more diverse relatively, compared to the end product, gastrulae have two or three germ layers and never more (Hall, 1999). Organ systems emerging from germ layers are similarly conserved: e.g. skin and nervous system arise from ectoderm, digestive tube from endoderm. A key outcome of the process of gastrulation is that sheets of cells come into contact, thus enabling the conserved embryonic inductions that are essential for the organization of the body plan during the phylotypic stage. These inductions between adjacent cell populations appear to form a stringent spatio-temporal constraint on the outcome of gastrulation, the starting point of the conserved phylotypic stage (Galis \& Sinervo 2002, Zalts \& Yanai 2017).

\section{Diversity of phylotypic stages among metazoa}

Phylotypic stages differ dramatically among phyla and classes, e.g. the segmented germband stage in insects and the neurula in vertebrates. This pattern of divergence and the conservation within phyla or classes suggests an early phase of rapid diversification in the evolution of metazoans, followed by strong conservation of these discrete taxon-specific stages (Buss 1987, Galis \& Sinervo 2002). Buss (1987) has proposed the following ingenious hypothesis for this phenomenon. The early rapid diversification occurred during the early, chaotic, phase in the evolution from unicellular to multicellular individuals (presumably during the Cambrian explosion). During this process, the level of selection shifted from individual cells to individual organisms. Early during this transition, mutations in cells that could gain access to reproduction had a chance to be maintained in future generations (as in plants). Later, when selection was firmly established at the level of the individual, heritable mutations became limited to those that occur in the germ-line, or in the short period before germ-line sequestration. This early rapid diversification scenario is intuitively appealing, but has received surprisingly little attention and hardly any research has been carried out to corroborate or falsify this important idea, like mutagenesis experiments with simple colonial organisms and theoretical modeling (Galis \& Sinervo 2002). 


\section{Evolutionary consequences - Influence on regeneration capacity}

The constraint on changes of early organogenesis has important consequences for regeneration capabilities. Regeneration usually involves recapitulation of normal development, once a regeneration blastema has been formed. Galis et al. (2003) proposed that regeneration is only possible for organs which develop as a semi-autonomous module and that do not require interactions with transient organs. Organ primordia typically appear during early organogenesis and hence the early development of most organs involves interactions with transiently present structures (e.g. somites, notochord, neural crest). This implies that this part of development cannot be easily replicated for regeneration purposes. Galis et al (2003) proposed that this explains why regeneration of the limbs is possible in many amphibians and lungfishes, but not in amniotes. In amphibians with metamorphosis, limb development is delayed relative to amniotes and has become decoupled from interactions with somites and other transient structures. Transplantation experiments show that limb buds develop as semi-independent, largely selforganizing modules (reviewed in Galis et al 2003). In lungfishes fins also develop after the phylotypic stage and regeneration of the bony skeleton of the fins is possible. Contrastingly, amniote limb buds show no self-organizing capacity and crucially depend on the presence of transient structures such as somites. In teleosts, the bony skeletons of the pectoral fins that is homologous with tetrapod limb bones also develops early and interactions with the transient somites are required. Regeneration of the bony skeleton is not possible (loc.cit.). Correspondingly, the global interactivity of phylotypic stages probably constrains the regeneration capacity in animals with burst organogenesis

\section{Evolutionary consequences -Influence on body plan evolution}

Most organ primordia appear during early organogenesis and, as we already discussed for digits in amniotes and cervical vertebrae in mammals, the evolutionary conservation of early organogenesis is, thus, probably implicated in the conservation of the number of repeated organs, see below for organ loss. Other examples of conserved numbers that are determined during early organogenesis include limbs and antennae in insects, and pharyngeal arches, kidneys, eyes, ears and limbs in vertebrates. The medical and veterinary literature shows that mutations for duplications occasionally occur, e.g. spleens, kidneys, ureters, vaginas, penises, testicles, digits, and even extremely rarely additional arms and legs, although additional legs are sometimes remnants of conjoined twins (e.g. Uchida et al. 2006, Lilje et al. 2007, Galis \& Metz 2007). These duplications appear to be strongly selected against, due to associated deleterious pleiotropic effects (Grüneberg 1963, Lande 1978, Lilje et al 2007, Galis et al 2006, Biesecker 2011).

\section{Evolutionary loss of organs}

The constraint against changes of the phylotypic stage is also implicated in the constraint on the evolutionary loss of organs. The loss of organs typically occurs via the slowly continued evolution of earlier developmental arrest, followed by degeneration (Lande 1978, Bejder \& Hall 2002, Galis et al. 2002b). This is presumably because the early interactions involving the organ primordia cannot easily be missed for normal development (Galis et al 2002b, 2010). As a result, generally more primordia are developed during embryogenesis than persist. For instance in horses and cows initially five digit condensations still develop (Galis et al 2002b). Similarly, 
when eyes are lost in cave fishes and salamanders, development always proceeds until the lenses have been formed, after which degeneration follows (e.g. Dufton et al. 2012). Other examples of vestigial organs are wings in emus and kiwis, pelves in whales, teeth in baleen whales and the clavicle in canids, felids and lagomorphs (Glover 1916, Klima 1990, Bejder \& Hall 2002, Senter et al. 2015). As a result of the slow accumulation of mutations during the loss of complex organs, re-evolution is virtually impossible, in agreement with Dollo's law (Goldberg \& Igič 2008, Galis et al. 2010).

\section{Weaker constraint against late emerging organ primordia}

In contrast, when the final numbers of organs is determined after the vulnerable phylotypic stage, when development is more modular, the constraint on changes is considerably weaker. In arthropods with sequential production of segments continuing past the conserved segmented germband stage, segment numbers are highly variable. An interesting exception to the variability is the number of segments of centipedes, which is variable, but always odd (Minelli \& Bortoletto 1988, Arthur \& Farrow 1999). This constancy appears to be caused by the conserved oscillatory pattern generation of two segments per cycle, hence variation is caused by the number of cycles with the cycling set up during the phylotypic stage (Chipman et al. 2004), Examples of late determined structures in amniotes are carpal and tarsal elements, phalanges, teeth, trunk and caudal vertebrae and nipples in mammals, which are all highly evolvable. In agreement with the weaker conservation of later determined numbers, changes of the number of thoracic vertebrae experience considerably weaker stabilizing selection in humans than changes of cervical vertebrae and are not significantly associated with congenital abnormalities (weaker pleiotropy, Galis et al. 2006). Similarly, in long-necked birds and reptiles, where the cervicothoracic boundary is determined at a later stage, there is substantial intraspecific variation in the number of cervical vertebrae (e.g. 22-25 in swans, Woolfenden 1961), in contrast to amniotes with necks with eight or fewer vertebrae, (Hofstetter \& Gasc 1969).

\section{Evolution of novelties and relaxed selection}

On rare occasions pleiotropic constraints are broken and novelties evolve.This is usually associated with a relaxation of the normally strong stabilizing selection (Galis \& Metz 2007, Varela-Lasheras et al. 2011). Periods of relaxed selection may be the colonization of new habitats, the disappearance of predators and the ample availability of new types of prey. Relaxed selection allows such novelties to persist for some time and this may lead to a reduction of the pleiotropic connections through small reorganizations of the developmental pathways, so that when stabilizing selection again increases, the chance for further persistence is increased. Such periods of relaxed selection are, thus, most likely associated with the initial phase of adaptive radiation and with the emergence of key innovations (Galis 2001, Galis \& Metz 2007). A good example can be found in the Semionotus fishes that invaded newly formed rift lakes in northeastern America in the late Triassic and early Jurassic and that radiated into a species clade (McCune 1990). McCune found that in the early history of the lake, when supposedly, directional selection was strong but stabilizing selection weak, many dorsal-ridge-scale anomalies occurred. Gradually, these anomalies became less prevalent, but interestingly some of the anomalies became incorporated into new body plans (McCune 1990). Other examples can be found in pets, where stabilizing selection is much reduced as a result of human care. As discussed above, polydactyly is strongly evolutionarily constrained among amniotes, despite the 
frequent occurrence of mutations for it. In contrast, polydactyly is particularly common in cats and dogs and in some dog breeds the breed standard even requires them to have one or two extra toes (Galis et al. 2001). Pet dogs with congenital abnormalities can breed and reproduce, although longevity is reduced (Galis \& Metz 2007). At the same time, there has been strong selection for differences in sizes and shapes (e.g. Kemp et al. 2005). The combination of strong directional selection and relaxed stabilizing selection orthogonal to it has led to the present extreme variation among dog breeds.

Internal factors can also relax stabilizing selection and this probably plays a role in the exceptional number of cervical vertebrae in sloths (six) and manatees (six to nine) (Galis 1999, Varela-Lasheras et al 2011). Sloths and manatees frequently have congenital abnormalities, in particular skeletal abnormalities that are also common in humans with an abnormal number of cervical vertebrae (Ten Broek et al 2012). However, the abnormalities appear to have hardly any effect on fitness, presumably due to the animals' extremely low activity (Varela-Lasheras et al 2011). An additional reason for the weaker constraint may be much reduced cancer rates in manatees (and probably sloths), associated with their low metabolic rates (Galis \& Metz 2003). Childhood cancers are among the pleiotropic effects associated with cervical ribs in humans (Galis 1999). Lower cancer rates may also be implicated in the weaker constraint against changes of the number of cervical vertebrae in birds and reptiles. Despite their high metabolic rates, birds have particularly low cancer rates, much lower than in mammals (Galis 1999, Galis \& Metz 2003).

Thus, the difficulty for breaking specific constraints varies among taxa, due to differences in the history of selection regimes (i.e. periods of relaxed stabilizing selection) and due to differences in specific pleiotropic effects associated with certain traits.

\section{Conclusions}

The complex and highly controlled global interactivity associated with mitosis and early organogenesis leads to pleiotropic constraints against evolutionary changes of developmental interactions. This strong control, which intensifies the interactivity, is essential because of the complexity of the processes and the grave consequences of disruptions (aneuploidy, apoptosis, cancer, sterility, death). As we have shown, mutations with an effect during such highly interactive states almost unavoidably have many deleterious pleiotropic effects that drastically reduce the chance that the mutations will be successful. Conservation is a consequence of consistently strong stabilizing selection against mutations via their pleiotropic effects (Galis et al. 2001, 2002a; Hansen \& Houle 2008). As the interactivity is part of developmental processes, the constraints can be considered to be developmental constraints.

We found very few examples of developmental constraints that act long term in the literature, the only additional well-doecumented one being developmental constraints against parthenogenesis (Engelstaedter 2008, see also the last part of section 2). In this case the tightly controlled global interactivity in the cell during meiosis probably plays a role, comparable to the interactivity of mitosis and the phylotypic stage.

The strongest and most universal of the constraints is that in metazoans differentiated cells cannot divide by mitosis (Buss 1987). The only possibility for differentiated cells to divide appears to be first to dedifferentiate, as happens in wound healing and regeneration (and cancer). The constraint places crucial restrictions on the order and timing of proliferation and differentiation during development and consequently on the potential for body plan evolution. 
The constraint on evolutionary changes of phylotypic stages may be weaker. Most notably, many phyla and classes have highly diverse phylotypic stages that evolved during early metazoan evolution (Buss 1987, Galis \& Sinervo 2003). Nonetheless, within many of these taxa, e.g. vertebrates and insects, evolutionary changes of this stage are highly constrained. This has grave consequences for the conservation of body plans, because most organ primordia appear during this stage and, hence, there is strong conservation of the numbers and earliest development of most organs.

\section{Box 1. Some a priori considerations}

The term constraint means restriction relative to a set of possible options. However, in biological writing the latter set is often left somewhat implicit. In quantitative genetics the term refers to the differential responsiveness to selection in the directions of the principal components of the genetic covariance matrix in proportion to their size. In particular, any zero principal component corresponds to a hard, i.e., dictionary style, constraint (c.f. Walsh \& Blows 2009). Although little is known yet about the prevalence of such zero principal components, the general tendency in high dimensional biological data is that principal components peter out roughly exponentially, suggesting that hard constraints will be extremely rare, except when directly caused by a physical conservation law. This unlikeliness becomes even greater since mutational covariance matrices, and thus their principal components, generally change with progressive evolution.

Another issue is that in practice our view on constraints on change depends on the time scale. In evolutionary biology it pays to distinguish at least between micro-evolution (changes in gene frequencies on a population dynamical time-scale), meso-evolution (the evolution of quantitative traits through repeated mutant substitutions and the concomitant evolutionary diversification) and macro-evolution (large scale changes, such as innovations that cannot be captured in terms of a fixed set of quantitative traits). Quantitative genetics and adaptive dynamics (e.g. Metz 2012) provide the main frameworks for dealing with trait evolution on the micro- and meso-evolutionary scales respectively while macro-evolutionary discourse is dominated by arguments from functional morphology and evo-devo.

For smooth genotype to phenotype maps the effect of small changes in gene expression is bound to be locally additive. In that case we can treat the micro-evolutionary process as governed by additive genetics. We can then equivalently argue in terms of mutant substitutions instead of shifts of the standing genetic variation. However, the genotype-to phenotype map invariably is nonlinear in the large. Moreover, phenotypic change on that scale influences the fitness landscape through its effect on the ecology; adaptive dynamics focuses on the effects of the latter change.

Meso-evolution presumably is largely driven by mutations with small effect. This expectation has both a mechanistic and a Darwinian reason. Most trait evolution appears to be regulatory (e.g. Gehrke \& Shubin 2015, Maeso et al 2017). Most mutational changes in the regulatory mechanisms may be expected to result in small changes in the levels of the relevant proteins at different points and times in the body, and thus to small changes in development, physiology and behaviour. In addition, mutations with large effect tend to bring an otherwise harmoniously operating system in disarray and will therefore contribute little to mesoevolutionary change. The ecology mediated changes in invasion fitnesses (e.g. Metz 2008) that drive meso-evolution thus tend to be minor relative to the fitness effects deriving from the need 
for a well-concerted organismal development and functioning. The latter effects presumably also underlie most macro-evolutionary regularities.

Together the above considerations support the metaphor of meso-evolution as a smooth uphill movement along the crests of a high dimensional fitness landscape, with the relatively featureless landscape on top of the crests continually changing thanks to the ecologically mediated feedback from traits to fitnesses. The gross landscape structure, on the other hand, stays roughly constant as it is dominated by internal selection, i.e., the need for organisms to stay well concerted (Metz JAJ. 2011). Thoughts on the geometry of meso-evolution: collecting mathematical elements for a post-modern synthesis. In The Mathematics of Darwin's Legacy, ed. FACC Chalub and JF Rodrigues, pp. 197-234. Basel: Birkhauser. On macro-evolutionary scales trait spaces themselves change through innovations. Otherwise macro-evolution is guided by large scale landscape features, with little chance for the effects of the genetic covariances to leave a visible trace (for the corresponding quantitative genetics see Walsh \& Blows 1.c.).

Gehrke AR, Shubin N. 2016. Cis-regulatory processes in the development and evolution of paired appendages. Sem. Cell Devel. Biol. 57:31-39

Maeso I, Acemel RD, Gomez-Skarmeta RD. 2017. Cis-regulatory landscapes in development and evolution. Curr. Opin. Genet. Dev. 43:17-42

Metz JAJ. 2008 Fitness. Pp. 1599-1612 In: Evolutionary Ecology, ed. SE Jørgensen, BD Fath, pp. 1599-1612. Encyclopedia of Ecology vol 2. Oxford: Elsevier

Metz JAJ. 2011. Thoughts on the geometry of meso-evolution: collecting mathematical elements for a post-modern synthesis. In The Mathematics of Darwin's Legacy, ed. FACC Chalub and JF Rodrigues, pp. 197-234. Basel: Birkhauser

Metz JAJ. 2012 Adaptive Dynamics. In: Encyclopedia of Theoretical Ecology, ed. A Hastings, LJ Gross, pp 7-17. Berkely: California University Press

6. Acknowledgements.

We thank Douglas Futuyma for discussion and many helpful comments.

\section{Literature cited}

Adam MP. 2012. The all-or-none phenomenon revisited. Birth Defects Res. A: Clin. Mol. Teratol. 94:664-669

Afelik,S., Rovira, M. 2017. Pancreatic $\beta$-cell regeneration: Facultative or dedicated progenitors? Mol. Cell. Endocrin. 445: 85-94

Akhshabi S, Sarda S, Dovrolis C, Yi S. 2015. An explanatory evo-devo model for the developmental hourglass F1000 Res. 3:156

Alieva IB, Vorobjev IA. 2004. Vertebrate primary cilia: a sensory part of centrosomal complex in tissue cells, but a "sleeping beauty" in cultured cells? Cell Biol. Int. 28:139-150

Amundson R. 1994. Two concepts of constraint: Adaptationism and the Challenge from Developmental Biology. Phil. Sci. 61:556-578

Arthur W, Farrow M. 1999. The pattern of variation in centipede segment number as an example of developmental constraint in evolution. J. Theor. Biol. 200:183-191

Azimzadeh J, Wong ML, Downhour DM, Sánchez Alvarado A, Marschall WF. 2012. Centrosome loss in the evolution of planarians. Science 27:461-463

Baguñà JSE, Auladell C. 1989. Regeneration and pattern formation in planarians. III. evidence that neoblasts are totipotent stem cells and the source of blastema cells. Development 107:77-86 
Barton NH,Turelli M. 1989. Evolutionary quantitative genetics: how little do we know? Ann. Rev. Genet. 23:337-370

Basten SG, Giles, RH. 2013. Functional aspects of primary cilia in signaling. Cell cycle and tumorigenesis. Cilia 2:6

Basto R, Lau J, Vinogradova T, Gardiol A, Woods CG, Khodjakov A, Raff JW. 2006. Flies without centrioles. Cell 125:1375-1386

Basto R, Brunk K, Vinogradova T, Peel N, Franz A, Khodjakov A, Raff JW. 2008. Centrosome amplification can initiate tumorigenesis in flies. Cell 133:1032-1042

Beamish CA, Strutt BJ, Arany EJ, Hill DJ. 2016. Insulin-positive, Glut2-low cells present within mouse pancreas exhibit lineage plasticity and are enriched within extra-islet endocrine cell clusters. Islets. 8:65-82

Bejder L, Hall BL. 2002. Limbs in whales and limblessness in other vertebrates: mechanisms of evolutionary and development transformation and loss. Evol. Devel. 4:445-458

Beukenboom LW, Vrijenhoek R. 1998. Evolutionary genetics and ecology of sperm-dependent parthenogenesis. J. Evol. Biol. 11:755-782

Bell G. 1982. The masterpiece of nature: The evolution and genetics of sexuality. London: Croomhelm

Bell G. 1989. Darwin and biology. J. Hered. 80:417-421

Biesecker LG. 2011. Polydactyly: how many disorders and how many genes? 2010 update. Dev. Dyn. 240:931-42

Bogdanović, Smits AH, de la Calle Musienes E, Tena JJ, Ford E, Williams R, Senanayake U, Schultz MD et al. 2016. Acitve DNA demethylation enhancers during the phylotypic period. Nature Genet. 48:417-426Bonaccorsi S, Giansanti MG, Gatti M. 2000. Spindle assembly in Drosophila neuroblasts and ganglion mother cells. Nature Cell Biol. 2:54-56

Bornens M 2012. The centrosome in cells and organisms. Science 335:422-426

Boveri T. 1901. Zellenstudien: Über die Natur der Centrosomen. 4. Jena, Germany: Fischer.

Boveri T. 1902.Über mehrpolige Mitosen als Mittel zur Analyse des Zellkerns. Verh. D. Phys. Med. Ges. Wurzberg N. F. 35:67-90; In English: Translated and annotated by H. Harris: Boveri T. 2008. Concerning the origin of malignant tumours by Theodor Boveri.. J. Cell Sci. 121 (Suppl. 1):1-84

Brennand K, Huangfu D, Melton D. 2007. All $\beta$ cells contribute equally to islet growth and maintenance. PLoS Biol. 5 (7):e163

Breunig et al. 2008. Primary cilia regulate hippocampal neurogenesis by mediating sonic hedgehog signaling. Proc. Nat. Acad. Sci. USA 105:13127-13132

Brinkley BR 1985. Microtubule organizing centers. Ann. Rev. Cell Biol. 1:145-172

Brockes JP 1997. Amphibian limb regeneration: rebuilding a complex structure. Science 276:8187

Buss L.W. 1987. The evolution of individuality. New Jersey: Princeton University Press

Chen JW, Zahid S, Shilts MH, Weaver SJ, Leskowitz RM, Habbsa S, Aronowitz D, Rokins KP, Chang Y, Pinnella Z, Holloway L, Mansfield JH. 2013. Hoxa-5 acts in segmented somites to regulate cervical vertebral morphology. Mech. Dev.130:226-40

Cheng X, Ho Jam Hui J, Lee YY, Tik Wan Law P, Shan Kwan H. 2015. A “developmental hourglass" in fungi. Mol. Biol. Evol. 32:1556-1566.

Chipman A, Arthure W, Akam M. 2004. A double segment periodicity underlies segment generation in centipede development. Curr. Biol. 14:1250-1256 
Conner JK 2012. Quantitative genetic approaches to evolutionary constraint: how useful? Evolution 66:3313-3320

Cordes R, K. Schuster-Gossler K, Serth K, Gossler A. 2004. Specification of vertebral identity is coupled to notch signalling and the segmentation clock. Development 131:1221-1233

Courtois A, Schuh M, Ellenberg J, Hiiragi T. 2012. The transition from meiotic to mitotic spindle assembly is gradual during early mammalian development. J. Cell Biol. 198:357-70

Cridge AG, Dearden PK, Brownfield LR. 2016. The mid-developmental transition and the evolution of animal body plans. Ann. Bot. 117: 833-843

Davis JC, Brandman O, Petrov DA. 2005. Protein evolution in the context of Drosophila development. J. Mol. Evol. 60: 774-785

Dawe HR, Farr H, Gull K. 2007. Centriole/basal body morphogenesis and migration during ciliogenesis in animal cells. J. Cell Sci. 120:7-15

De Mendoza A, Sebé-Pedrós A, Šestak MS, Matejcic M, Torruella G, Domazet-Lošo T, RuizTrillo I. 2013. Transcription factor evolution in eukaryotes and the assembly of the regulatory toolkit in multicellular lineages. Proc. Natl. Acad. Sci. USA 110:E4858-E4866

Deschamps J, Duboule D. 2017. Embryonic timing, axial stem cells, chromatin dynamics and the Hox clock. Genes Devel. 31:5-6

Diez del Corral R, I. Olivera-Martinez A, Goriely E, Gale M, Maden M, Storey K. 2003. Opposing FGF and retinoid path- ways control ventral neural pattern, neuronal differentiation, and segmentation during body axis extension. Neuron 40:65-79

Dingemans KP. 1969. The relation between cilia and mitoses in the mouse. J. Cell Biol. 43:361367

Domazet-Lošo T, Tautz D. 2010. A phylogenetically based transcriptome age index mirrors ontogenetic divergence patterns. Nature 468:815

Dor Y, Brown J, Martinez OI, Melton DA. 2004. Adult pancreatic beta-cells are formed by selfduplication rather than stem-cell differentiation. Nature 420:41-46

Drost H-G, Gabel A, Grosse I, Quint M. 2015. Evidence for active maintenance of phylotranscriptomic hourglass patterns in animal and plant embryogenesis. Mol. Biol. Evol. 32:1221-1231.

Duboule D. 1994. Temporal colinearity and the phylogenetic progression: a basis for the stability of the vertebrate Bauplan and the evolution of morphologies through heterochrony. Development (Suppl) 135-142

Dubrulle J, Pourquié O. 2004. Fgf8 mRNA decay establishes a gradient that couples axial elongation to patterning in the vertebrate embryo. Nature 427:419-422

Dudka D, Meraldi P. 2017. Symmetry does not come for free: cellular mechanisms to achieve a symmetric cell division. In: Tassan JP., Kubiak J. (eds) Asymmetric Cell Division in Development, Differentiation and Cancer. Results and Problems in Cell Differentiation, vol 61. Springer Nature, Cham, Switzerland

Dufton M, Hall BK, Franz-Odendaal TA. 2012. Early lens ablation causes dramatic long-term effects on the shape of bones in the craniofacial skeleton of Astyanax mexicanus. PLoS One 7:e50308

Dustin ML. 2014. T cells play the classics with a different spin. Mol. Biol. Cell. 25:1699-703

Eisman RC, Kaufman TC 2007. Cytological investigation of the mechanism of parthenogenesis in Drosophila mercatorum. Fly 1:317-329

Engelstädter J. 2008. Constraints on the evolution of asexual reproduction. BioEssays 30:11381150 
Evans MJ, Shami SG, Cabral-Anderson LJ, Dekker NP. 1986. Role of non-ciliated cells in renewal of the bronchial epithelium of rats exposed to NO2. Am. J. Pathol. 123:1226-133

Ferree PM, McDonald K, Fasulo B, Sullivan W. 2006. The origin of centrosomes in parthenogenetic hymenopteran insects. Curr. Biol. 16:801-807

Finetti F, Rossi Paccani S, Riparbelli MG, Giacomello E, Perinetti G, Pazour GJ, Rosenbaum J, Baldari CT. 2009. Intraflagellar transport is required for polarized recycling of the TCR/CD3 complex to the immune synapse. Nat. Cell Biol. 11:1332-1339

Fonte VG, Searls RL, Hilfer SR. 1971. The relationship of cilia with cell division and differentiation. J. Cell Biol. 49:226-229

Futuyma D. 2010. Evolutionary constraint and ecological consequences. Evolution 6:1865-1884

Galis F. 1999. Why do almost all mammals have seven cervical vertebrae? Developmental constraints, Hox genes and cancer. J Exp Zool (Mol Dev Evol) 285:19-26.

Galis F. 2001. Key innovations and radiations. In: The character concept in evolutionary biology, ed. GP Wagner, pp 581-605. London: Academic Press.

Galis F, van Alphen JJM, Metz JAJ. 2001. Why five fingers? Evolutionary constraints on digit numbers. Trends Ecol Evol 16:637-46

Galis, F, Metz JAJ. 2001. Testing the vulnerability of the phylotypic stage: on modularity and evolutionary conservation. J. Exp. Zool. B 291, 195-204.

Galis F, Metz JAJ. 2003. Anti-cancer selection as a source of developmental and evolutionary constraints. BioEssays 25:1035-9.

Galis F, Van Dooren TJM, Feuth H, Ruinard S, Witkam A, Steigenga MJ, Metz JAJ, Wijnaendts LCD. 2006. Extreme selection against homeotic transformations of cervical vertebrae in humans. Evolution 60:2643-54

Galis F, Metz JAJ. 2007. Evolutionary novelties: the making and breaking of pleiotropic constraints. Integr. Comp. Biol. 47:409-419

Galis F, van Alphen JJM, Metz JAJ. 2001. Why five fingers? Evolutionary constraints on digit numbers. Trends Ecol Evol 16:637-46

Galis F, van Alphen JJM, Metz JAJ. 2002b. Digit reduction: via repatterning or developmental arrest? Evol. Devel. 4, 249-251

Galis F, Arntzen JW, Lande R. 2010. Dollo's law and the irreversibility of digit loss in Bachia. Evolution 64:2466-2476

Galis F, Van Dooren TJM, Feuth H, Ruinard S, Witkam A, Steigenga MJ, Metz JAJ, Wijnaendts LCD. 2006. Extreme selection against homeotic transformations of cervical vertebrae in humans. Evolution 60:2643-54

Galis F, Van Dooren TJM, Metz JAJ. 2002a. Conservation of the segmented germband stage: robustness or pleiotropy? Trends Genet 18:504-9.Gentile L, Cebria F, Bartscherer K. 2011. The planarian flatworm: an in vivo model for stem cell biology and nervous system regeneration. Disease Mod. Mechan. 4:12-19

Gibson G, Wagner GP. 2000. Canalization in evolutionary genetics: a stabilizing theory? Bioessays 22:372-380

Gilbert SF, Raunio AM 1997. Embryology: constructing the organism. Sunderland, MA: Sinauer Associates.

Godinho SA, Pelman D. 2014. Causes and consequences of centrosome abnormalities in cancer. Phil. Trans. Royal Soc. B 369:20130467

Goldberg EE, Igič B. 2008. On phylogenetic tests of irreversible evolution. Evolution 62:27272741 
Gönczy P. 2015. Centrosomes and cancer: revisiting a long-standing relationship. Nature Rev. $15: 639-652$

Goto H, Inaba H, Inagaki M. 2017. Mechanisms of ciliogenesis suppression in dividing cells. Cell. Mol. Life Sci. 74:881-890

Grifone R, Kelly RG 2007. Heartening news for head muscle development. Trends Genet. 23:365-369

Hadorn E. 1961. Developmental Genetics and Lethal Factors. Methuen and Co LTD (1961)

Hall BK. 1997. Phylotypic stage or phantom: is there a highly conserved embryonic stage in vertebrates? Trends Ecol. Evol. 12:461-463

Hall BK. 1999. Evolutionary developmental biology, 2nd edition. Dordrecht: Kluwer Academic Press.

Hansen TF, Houle D. 2008. Measuring and comparing evolvability and constraint in multivariate characters. J. Evol. Biol. 21:1201-1291.

Henneguy LF. 1898. Sur les rapports des cils vibratiles avec les centrosomes. Arch. d'Anat. Micr. 1:481-496

Hill WG, Zhang X-S. 2012. On the pleiotropic structure of the genotype-phenotype map and the evolvability of complex organisms. Genetics 190:1131-1137

Hiruta C, Nishida C, Tochinai S. 2010. Abortive meiosis in the oogenesis of parthenogenetic Daphnia pulex. Chromosome Res. 18: 933-840

Hu H, Uesaka M, Guo S, Shimai K, Lu S-M, Li F, Fujimoto S, Ishikawa M, Liu S, Sasagawa Y, Zhang G, Kuratani S, Yu J-K, Kusakabe TG, Khaitovich P, Irie N 2017. Constrained vertebrate evolution by pleiotropic genes. Nature Ecol. Evol. 1:1722-1730

Irie N, Kuratani S. 2011. Comparative transcriptome analysis reveals vertebrate phylotypic period during organogenesis. Nature Comms. 2:248

Jacquet P. 2004. Sensitivity of germ cells and embryos to ionizing radiation. J. Biol. Regul. Homeost. Agenets 18:106-114

Kacser H, Burns, JA 1981. The molecular basis of dominance. Genetics, 97:639-666

Kelly RG 2012 The second heart field. Curr. Top. Devel. Biol. 100:33-65

Keyte A, Hutson MR. 2012. The neural crest in cardiac congenital anomalies. Differentiation $84: 25-40$

Kalinka AT, Varga KM, Gerrard DT, Preibisch S, Corcoran DL, Jarrells J, Ohler U, Bergman CM, Tomancak P. 2010. Gene expression divergence recapitulates the developmental hourglass model. Nature 468:811-816

Karsenti E. 2008. Self-organization in cell biology: A brief history. Nat. Rev. Mol. Cell Biol. 9:255-262

Ke Y-N, Yang W-X. 2014. Primary cilium: an elaborate structure that blocks cell division? Gene 547:175-185

Kemp TJ, Bachus KN, Nairn JA, Carrier DR. 2005. Functional trade-offs in the limb bones of dogs selected for running versus fighting. J. Exp. Biol. 208:3475-3482

Kirkpatrick M, Lofsvold D 1992. Measuring selection and constraint in the evolution of growth. Evolution 46:954-971

Klima, M. 1990a. Rudiments of the clavicle in the embryos of whales. Zeitschr.f. Saügetierk. 55: 202-212

Lancaster MA Schroth J, Gleeson JG. 2011. Subcellular spatial regulation of canonical Wnt signaling at the primary cilium. Nat. Cell Biol. 13:700-707.

Lande R.1978. Evolutionary mechanisms of limb loss in tetrapods. Evolution 32:73-92 
Lande R. 1980. The genetic covariance between characters maintained by pleiotropic mutations. Genetics 94:203-215

Lenhossék Mv 1898. Ueber Flimmerzellen. Verhandl. Der Anat. Gesel. Kiel 12:106-128.

Levin M, Hashimshony, Wanger F, Yanai I. 2012. Developmental milestones punctuate gene expression in the Caenorhabditis embryo. Devel. Cell 22:1101-1108.

Lilje C, Finger LJ, Ascuitto RJ 2007. Complete unilateral leg duplication with ipsilateral renal agenesis. Acta Paediatrica 96:461-471

Ludeman DA, Farrar N, Riesgo A, Paps J, Leys SP. 2014. Evolutionary origins of sensation in metazoans: functional evidence for a new sensory organ in sponges. BMC Evol. Biol. 14:3

Maia AR, Zhu X, Miller P, Gu G, Maiato H, Kaverina I. 2013. Modulation of Golgi-associated microtubule nucleation throughout the cell cycle. Cytoskeleton 70:32-43

Mahjoub M, Stearns T. 2012. Supernumerary centrosomes nucleate extra cilia and compromise primary cilium signaling. Current Biol. 22:1628-1634

Manandhar G, Schatten H, Sutovsky P. 2005. Centrosome reduction during gametogenesis and its significance. Biol Reprod. 72:2-13.

Margulis L 1981 Symbiosis and cell evolution. San Francisco: Freeman.

Masuda M, Sato H. 1984. Asynchronization of cell division is concurrently related with ciliogenesis in sea urchin blastulae. Develop. Growth Differ. 26:281-294.

Maynard Smith J, Burian R, Kauffman S, Alberch, P, Campbell J, Goodwin B, Lande R, Raup D., Wolpert L.1985. Developmental constraints and evolution. Quart. Rev. Biol. 60:265-287

McCune AR. 1990. Morphological anomalies in the Semionotus complex: relaxed selection during colonization of an expanding lake. Evolution 44:71-85

Melzer R, Theißen G. 2016. The significance of developmental robustness for species diversity. Ann. Bot. 117:725-732

Meraldi P. 2016. Centrosomes in spindle organization and chromosome segregation: a mechanistic view. Chromosome Res. 24:19-34

Minelli A, Bortoletto, S 1988. Myriapod metamerism and arthropod segmentation. Biol. J. Linn. Soc. Lond. 33, 323-343

Müller G, Wagner GP. 1991. Novelty in evolution. Restructuring the concept. Ann. Rev. Ecol. Syst. 22:229-256

Ninomiya, H, Elinson RP, Winklbauer R. 2004. Antero-posterior tissue polarity links mesoderm convergent extension to axial patterning. Nature 430:364-367

Ninova M, Ronshaugen M, Griffiths-Jones S. 2014. Conserved temporal patterns of MicroRNA expression in Drosophila support a developmental hourglass model. Genome Biol. Evol. 6:2459:2467

Ohazama A, Haycraft CJ, Seppala M, Blackburn J, Ghafoor S, Cobourne M, Martinelli DC et al. 2009. Primary cilia regulate Shh activity in the control of molar tooth number. Development 136:897-903

Opitz, JM, J. M. Fitzgerald, J. F. Reynolds, S. O. Lewin, A. Daniel, L. S. Ekblom, and S. Philips. 1987. The Montana fetal genetic pathology program and a review of prenatal death in humans. Am J. Med. Genet. Suppl. 3:93-112

Opitz JM, Zanni G, Reynolds JF Gilbert-Barness E. 2002. Defects of blastogenesis. Am J Med Genet 115:269-286

Oster G, Alberch P. 1982. Evolution and bifurcation of developmental programs. Evolution 36:444-4599 
Papakostas S, Vøllestad, LA, Bruneaux, M, Aykanat, T, Vanoverbeke, J, Ning, M, Primmer CR, Leder E. H. 2014. Gene pleiotropy constrains gene expression changes in fish adapted to different thermal conditions. Nature Communications, 5, 4071

Piasecka B, LichockiP, Moretti S, Bergmann S, Robinson-Rechavi M. 2013. The hourglass and the early conservation models - co-existing patterns of developmental constraints in vertebrates. PLoS Genet 9, pg. e1003476

Raff RA. 1996. The shape of life. Chicago: University of Chicago Press

Reumer JWF, Ten Broek CMA, Galis F. 2014. Extraordinary incidence of cervical

ribs indicates vulnerable condition in Late Pleistocene mammoths. PeerJ 2:e318

Razavi, R. Najafabade HS, Abdullah S, Smukler S, Arntfield M, van der Kooy D. 2015. Diabetes enhances the proliferation of adult pancreatic multipotent progenitor cells and biases their differentiation to more $\beta$-cell production. Diabetes 64, 1311-1323.

Rios RM. 2014. The centrosome-Golgi apparatus nexus. Philos. Trans. R. Soc. B Biol. Sci. 369:20130462.

Riparbelli MG, Stouthamer R, Dallai R, Callaini 1998. Parthenogenetic egg of the hymenopteran Muscidifurax uniraptor. Devel. Biol. 195:89-99Riparbelli MG, Callaini G. 2003 Drosophila parthenogenesis: a model for de novo centrosome assembly. Devel. Biol. 260:298313

Russell LB. 1950. X-ray induced developmental abnormalities in the mouse and their use in the analysis of embryological patterns. J Exp Zool 114:545-602

Sadler TW. 2010 Birth defects and prenatal diagnosis. In: Sadler TW, ed. Langman's Medical Embryology (ed 11). pp. 113-5. Baltimore, MD: Lippincott, Williams, and Wilkins

Sakata T, Chen JK. 2011. Chemical "Jekyll and Hyde's: small-moleculare inhibitors of developmental signaling pathways. Chem. Soc. Rev. 40:4318-4331

Salazar-Ciudad I, Jernvall J 2010. A computational model of teeth and the developmental origins of morphological variation. Nature. 464:583-586

Sander K. 1983. The evolution of patterning mechanisms: gleanings from insect embryogenesis and spermatogenesis. In: Development and evolution, ed. BC Goodwin, N Holder, CC Wylie, pp. 137-159. Cambridge: Cambridge University Press

Sander K, Schmidt-Ott U. 2004. Evo-Devo aspects of classical and molecular data in a historical perspective. J. Ep. Zool. B Mol. Dev. Evol. 15:69-91

Sandrock C, Vorburger C. 2011. Single-locus recessive inheritance of asexual reproduction in a parasitoid wasp. Curr. Biol. 21:433-437

Schoch RR. 2013. How body size and development biased the directon of evolution in early amphibians. Hist. Biol. 25:155-165 Scholtz G. 2000. Evolution of the Nauplius stage in malacostracan crustaceans. J. Zool. Syst. Evol. Research 38:175-187

Schwitalla S, Fingerle AA, Cammereri P Nebelsiek T 2013. Intestinal tumorigenesis initiated by dedifferentiation and acquisition of stem-cell-like properties. Cell 152:25-38

Seidel F. 1960. Körpergrundgestalt und Keimstruktur. Eine Erörterung über die Grundlagen der vergleichenden und experimentellen Embryologie und deren Gültigkeit bei phylogenetischen Überlegungen. Zool. Anz. 164:245-305

Senter P, Moch JG. 2015. A critical survey of vestigial structures in the postcranial skeletons of extant mammals. PeerJ 3:e1439

Shenefelt RE. 1972. Morphogenesis of malformations in hamsters caused by retinoic acid: relation to dose and stage at treatment. Teratology 5:103-118 
Sir J-H, Pütz M, Daly O, Morrison GG, Dunning M, Kilmartin JV, Gergely F 2013. Loss of centrioles causes chromosomal instability in vertebrate somatic cells. J. Cell Biol. 203:747-756 Slack JMW, Holland PWH, Graham CF. 1993. The zootype and the phylotypic stage. Nature 361:490-492.

Smukler SR, Arntfield ME, Razavi R, Bikopoulos G, Karpowicz P, Seaberg R, Dai F et al. 2011. The adult mouse and human pancreas contain rare multipotent stem cells that express insulin. Cell. Stem. Cell 8:281-293

Sorokin SP 1968. Reconstructions of centriole formation and ciliogenesis in mammalian lungs. J. Cell Sci. 3:207-230

Stergachis A, Neph S, Reynolds A, Humbert R, Miller B, Paige SL, Vernot B, Cheng JB et al. 2013. Developmental fate and cellular maturity encoded in human regulatory DNA landscapes. Cell 154:888-903Stiess M, Maghelli N, Kapitein LC, Gomis-Rüth S, Wilsch- Bräuninger M, Hoogenraad CC, Tolic-Nørrelykke IM, Bradke F: Axon extension occurs independently of centrosomal microtubule nucleation. Science 2010, 327:704-707

Tanaka EM, Reddien PW. 2011. The cellular basis for animal regeneration. Dev. Cell 21:172185

Ten Broek CMA, Bakker AJ, Varela-Lasheras I, Bugiani M, Van Dongen S, Galis F. 2012. Evodevo of the human vertebral column: on homeotic transformations, pathologies and prenatal selection. Evol. Biol. 39:456-471

Teta M, Rankin MM, Long SY, Stein GM, Kushner JA. 2007. Growth and regeneration of adult beta cells does not involve specialized progenitors. Dev. Cell 12, 817-825.

Tram U, Fredrick K, Werren JH, Sullivan W. 2006. Paternal chromosome segregation during the first mitotic division determines Wolbachia-induced cytoplasmic incompatibility phenotype. $J$. Cell Sci. 119:3655-3663

Trestman M. 2013. The Cambrian explosion and the origins of embodied cognition. Biol. Theor. 8:80-92

Tsou M-FB \& Stearns T. 2006. Controlling centrosome number: licenses and blocks. Curr. Opin. Cell Biol. 18: 74-78

Uchida J, Naganuma T, Machida Y, Kitamoto K, Yamazaki T, Iwai T, Nakatani T. 2006. Modified extravesical ureteroneocystostomy for completely duplicated ureters in renal transplantation. Urol Int 77:104-6

Van der Geer, AAE, Galis F. 2017. High incidence of cervical ribs indicates vulnerable condition in Late Pleistocene woolly rhinoceroses. PeerJ 5:e3684

van Wolfswinkel JC, Wagner DE, Reddien PW. 2014. Single-cell analysis reveals functionally distinct classes within the planarian stem cell compartment. Cell Stem Cell. 15:326-339

Varela-Lasheras I, Bakker AJ, Van der Mije S, Van Alphen J, Galis F. 2011. Breaking

evolutionary and pleiotropic constraints in mammals: on sloths, manatees and

homeotic mutations. EvoDevo 2:11

Vincent SD, Buckingham ME 2010. How to make a heart: the origin and regulation of cardiac progenitor cells. Curr Top. Devel. Biol. 90:1-41

von Dassow G, Munro, EM.1999. Modularity in animal development and evolution: elements of a conceptual framework for EvoDevo. J. Exp. Zool. 285, 307-325

von Dassow G, Meir E, Munro EM, Odell GM. 2000. The segment polarity network is a robust development module. Nature 406, 188-192

Vermeij GJ. 2015. Forbidden phenotypes and the limits of evolution. Interface Focus 5:20150028 
Vermot J, Pourquié O. 2005. Retinoic acid coordinates somitogenesis and left-right patterning in vertebrate embryos. Nature 435:215-220

Wagner A. 2000. Robustness against mutations in genetic networks of yeast. Nat. Genet. 24:355-361

Wagner A. 2012. The role of robustness in phenotypic adaptation and innovation. Proc. Biol. Sci. 279:1249-1258

Walz G. 2017. Role of primary cilia in non-dividing post-mitotic cells. Cell Tissue Res. 369:1125

Wheatley 1995. Primary cilia in normal and pathological tissues. Pathobiology 63:222-238

Woolfenden GE. 1961. Postcranial morphology of the waterfowl. Bull. Florida State Mus. Biol. Sci. 6:1-129

Wu J, Akhmanova A. 2017. Microtubule-organizing centers. Ann Rev. Cell Dev. Biol. 33:4.14.25

Zakany J, Kmita M, Alarcon P, de la Pompa JL, Duboule D. 2001. Localized and transient transcription of Hox genes suggests a link between patterning and the segmentation clock. Cell 106:207-217

Zenker J, White MD, Templin RM, Parton RG, Thorn-Seshold O, Bissiere S, Plachta N. 2017. A microtubule-organizing center directing intracellular transport in the early mouse embryo. Science 357:925-928

Zalts H, Yanai I. 2017. Developmental constraints shape the evolution of the nematode middevelopmental transition. Nat. Ecol. Evol. 1(5):113 